\title{
Protective Coatings on Medical Implants by Reactive Diffusion
}

\author{
Elazar Y. Gutmanas ${ }^{1,2, a)}$ and Irina Gotman ${ }^{1, b)}$ \\ ${ }^{1}$ Department of Materials Science and Technology, Techion-Israel Institute of Technology, Haifa, 32000, Israel \\ ${ }^{2}$ National Research Tomsk Polytechnic University, Tomsk, 634050, Russia \\ a) Corresponding author: gutmanas@tx.technion.ac.il \\ b) gotman@tx.technion.ac.il
}

\begin{abstract}
Wear resistant and corrosion resistant surfaces are important for medical implants. Wear resistance is especially important for articulating surfaces in load bearing applications such as total hip and total knee replacements. Metal-on- polyethylene bearings result in relative large volumetric wear, ceramics such as alumina have an excellent wear resistance but are brittle, metal-on-metal bearings have good wear resistance, but release nanometric debris and ions that may cause allergy or have toxic effects. Hard ceramic coatings on metal substrates may be a good solution: low wear and low ion release and ductile metal alloy interior-no danger of brittle fracture and easy shaping. Ti alloys such as for example Ti-6Al-4 have the best combination of mechanical properties and biocompatibility, but have very poor wear resistance, $\mathrm{Co}-\mathrm{Cr}-\mathrm{Mo}$ have good wear resistance, but may cause allergy. TiN hard coatings deposited on Ti alloys by PVD have relatively poor adhesion to the substrate as a result limited durability. Hard coatings formed on the surface of Ti alloys, $\mathrm{Zr}$ as well as CoCrMo alloys by reactive diffusion have good adhesion to the substrate as a result of gradual change of composition and gradual change of hardness. Reactive diffusion coatings obtained employing developed Powder Immersion Reaction Assisted Coating (PIRAC) on articulating surfaces of Ti alloys and CoCrMo show excellent adhesion to the substrate. Total hip implants show good performance in wear simulator tests as well as in vivo tests in canine and rat models. The thickness of reactive diffusion coatings is proportional to square root from time. It is shown that that thicker TiN coatings can be obtained via 3 stage PIRAC process: nitriding followed by tiatanization and additional PIRAC nitriding. Similar approach in two stages - titanizaton followed by nitriding can be employed for processing on TiN based coatings on CoCrMo alloy. Duplex TiN coatin-TiN PIRAC coating followed by TiN plasma assisted PVD (PAPVD) results in thick coatings with excellent adhesion to the substrate. PIRAC titanization followed by was successfully used for conversion of $\mathrm{Ni}$ foam to NiTi Nitinol foam and formation of TiN coating on the surface of Nitinol foam, resulting in 10 fold decrease of $\mathrm{Ni}$ ions release into physiological solution. PIRAC nitriding was successfully used also for nitriding of TiNb alloys, $\mathrm{Zr}$ and $\mathrm{Zr}-2.5 \mathrm{Nb}$ alloy. Two stage coating by wear resistant TiN based layer can be applied to steels, BCC metals such as Mo and W and Ni based superalloys.
\end{abstract}

\section{INTRODUCTION}

Medical implants are working in corrosive media of physiological fluids and implants with articulating surfaces should be wear resistant to provide service for many years that corresponds usually to tens of millions of cycles. From materials or combinations of materials used currently metal-on-UHMWPE (ultra high molecular weight polyethylene) bearings result in relative large volumetric wear [1-3], ceramics such as alumina [4-6] have an excellent wear resistance but are brittle, that may cause fracture during accidents, metal-on-metal bearings (usually CoCrMo alloys) [7-9] have good wear resistance, but release nanometric debris and ions that may cause allergy or have toxic effects. The desired alternative combination should posses the high fracture toughness of metals and the wear performance of ceramics. The approach for achieving this is to combine a thin ceramic surface layer on a metallic substrate. In addition of having the desired tribological wear properties, the surface layer-ceramic film (coating) materials must be biocompatible and poses suitable mechanical properties and structural stability. For practical success of such technological approach the durability of the ceramic film on the metallic substrate is very

International Conference on Physical Mesomechanics of Multilevel Systems 2014

AIP Conf. Proc. 1623, 203-208 (2014); doi: 10.1063/1.4901481

(C) 2014 AIP Publishing LLC 978-0-7354-1260-6/\$30.00 
important. The ceramic coating must adhere to the metal so that it does not chip or delaminate from the surface under the stress and strain experienced during surgical implantation and clinical use. The coating must be cohesive within itself to resist fracture and shear during articulation and contact with third-body particles. The adhesive or cohesive failure of the ceramic coating would also result in release of hard third-body particles into the joint that will increase abrasive wear of the unprotected metal. Since no material is damage-proof, the ceramic coating should be able to tolerate localized accidental damage to the surface without progressive adhesive or cohesive failure.

There are a number of processes and materials that have been proposed, investigated, or implemented to create ceramic films on the surface of a metal [10-13]. One of the methods is to deposit a ceramic coating onto the metal surface for example by Physical Vapor Deposition (PVD) or Plasma Assisted PVD (PAPVD) [10, 14-17]. The mechanical properties of the ceramic are typically much different from those of the metal substrate that may result in adhesive failure between the two materials under load during articulation. Another method of creating the ceramic film is to diffuse or inject a nonmetallic element such as nitrogen into the surface and cause a phase transformation of the surface from metal to ceramic The rate of diffusion typically restricts this process so that either the coating is too thin or the processing time is very long. The main advantage of this approach is that a diffusional gradient of composition is associated with gradient in properties often resulting in low residual stresses and good adhesion of the coating to the substrate. Such approach is used for reactive diffusion of oxygen into $\mathrm{Zr}$ alloys with formation of relatively hard $\mathrm{ZrO} 2$ in the surface layer and oxygen hardened inner layer [18-21].

PIRAC (powder immersion reaction-assisted coating) nitriding has been proposed as an alternative nitriding method [22-25]. In PIRAC nitriding, a workpiece is annealed in a chromium rich steel container that prevents oxygen penetration while allowing for inward diffusion of atmospheric nitrogen. As a result, oxygen-free monatomic nitrogen environment is created on-site, without the use of vacuum pumps and nitrogen gas supply.

\section{EXPERIMENTAL}

In present research commercially pure titanium cp-Ti and Ti6Al4V alloy were used., as well as samples of CoCrMo alloy and Ti-Nb alloy. Ni foam from INCO was used for conversion into Nitinol-N-Ti Alloy. Speciens of various size were prepared by cutting, and their surface ground and polished with fine alumina powder $(0.05 \mathrm{~mm})$. Ti alloy samples were coated by PIRAC niriding. In brief, PIRAC can be described as the annealing of bulk ceramic parts immersed into metal powder. In PIRAC nitriding, the samples to be coated are immersed into the powder of an unstable nitride such as $\mathrm{Cr} 2 \mathrm{~N}$, that decomposes during heat treatment creating a low to moderate pressure of highly reactive monoatomic nitrogen. Alternatively, nitrogen can be supplied to the reaction zone by selective diffusion from the atmosphere. In the present work, the combination of both approaches was used, i.e. samples immersed into $\mathrm{Cr} 2 \mathrm{~N}$ powder were annealed in sealed containers made of a stainless steel foil (Fig. 1). The steel foil contains 26 wt.\% $\mathrm{Cr}$ that reacts with the atmospheric oxygen forming a very stable $\mathrm{Cr}$ oxide, $\mathrm{Cr} 2 \mathrm{O} 3$. This reaction prevents oxygen from penetrating through the container walls, so that the $\mathrm{O} 2$ pressure not exceeding $10-5 \mathrm{~Pa}-10^{-7}$ torr. is maintained inside the container without application of any vacuum pumps [26]. At the same time, $N$ atoms can easily diffuse through the container walls due to the rather low affinity of $\mathrm{Cr}$ which is the only nitride-forming element in the foil.

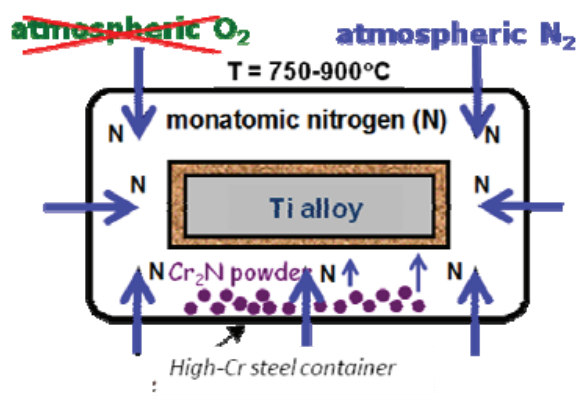

FIGURE 1. Schematic of PIRAC nitriding of specimen from Ti alloy

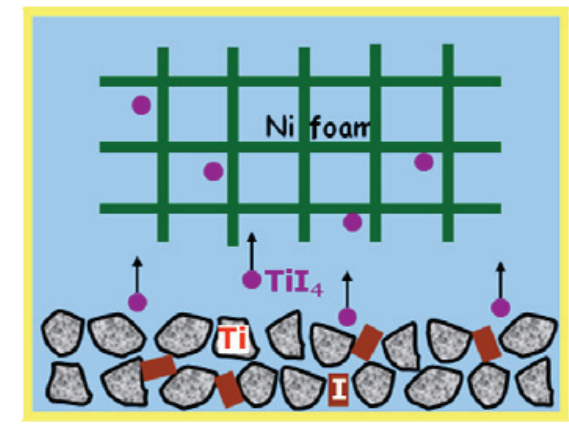

FIGURE 2. Schematic of PIRAC titanization: Ni foam as PIRAC titanization of various materials 

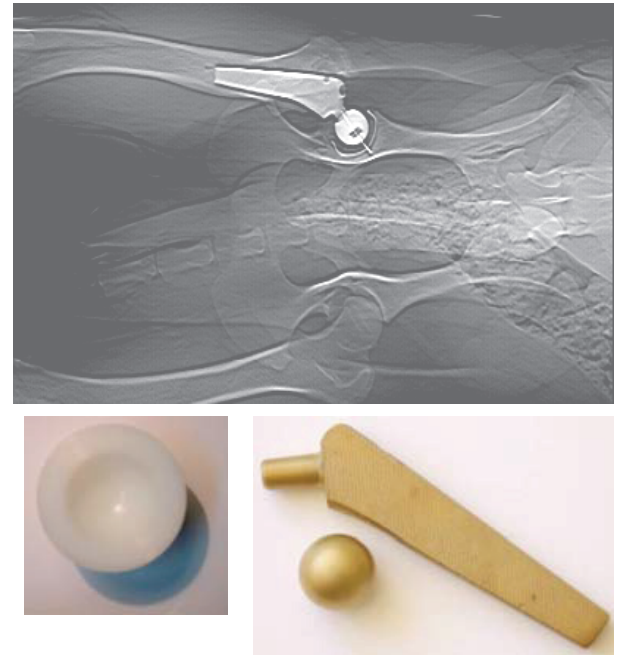

(a)
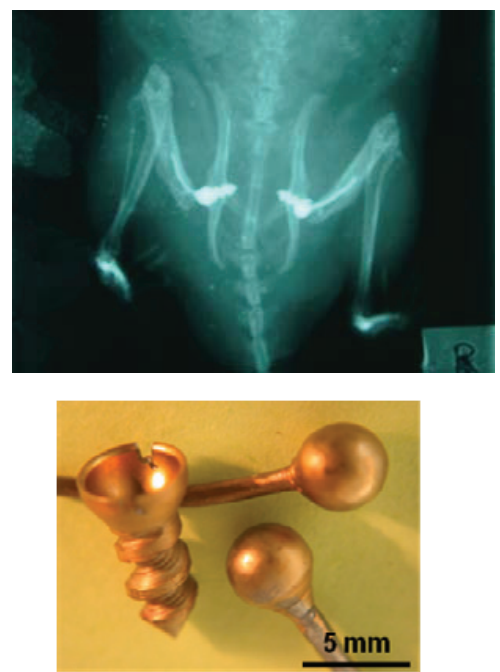

(b)

FIGURE 3. X-ray-radiology pictures (top) after implantation surgery and optical photographs of total hip implants (bottom) for dogs (a) and Wistar rats (b)

Both the diffusion of $\mathrm{N}$ from the atmosphere and the decomposition of $\mathrm{Cr} 2 \mathrm{~N}$ powder, create nitrogen pressure inside the container reaching the equilibrium pressure of $\mathrm{Cr} 2 \mathrm{~N}$ formation at the corresponding temperature, e.g. $2 \times 10^{2} \mathrm{~Pa}$ at $1000^{\circ} \mathrm{C}$. PIRAC nitriding as compared to PVD is not a line-of-sight process and therefore allows uniform treatment of complex shape components.

Similar approach was used for PIRAC titanization of specimens (see Fig. 2). In this case specimens Ni foam as an example) are placed in sealed stainless steel container with blend of Ti and iodine powder. Ti forms with iodine a volatile gas (Ti powder + I powder $\Rightarrow$ TiI4 gas) that transports Ti to the surface of the specimen where Ti reacts with the substrate, releasing iodine ( $\mathrm{Ni}+\mathrm{TiI} 4 \Rightarrow$ NixTiy $\Rightarrow \mathrm{NiTi})$. This is a typical transport reaction. Combination of PIRAC niriding and PIRAC titanization were employed for coating of various Ti alloys as well as for fabrication of hard TiN based coatings on other alloys via two or three stage process. Combination of PIRAC nitriding of Ti alloys followed by PVD nitriding was also employed.

In vivo tests with TiN PIRAC coated total hip Ti6Al4V joints were performed were on canine/dogs and Vistar rats models. 12 dogs and 10 rats underwent total hip arthroplasty.(THA). $12 \mathrm{~mm}$ diameter THA heads and acetabular cups for dogs and $4 \mathrm{~mm}$ diameter for rats were fabricated from Ti-6Al-4V alloy (as well as from $316 \mathrm{~L}$ stainless steel for rats) by machining followed by polishing of articulating surfaces. $1.5 \mu \mathrm{m}$ thick TiN/Ti2N hard coatings on Ti-6Al-4Vwere grown on the heads and cups by PIRAC nitriding at $900^{\circ} \mathrm{C}$ for $4 \mathrm{~h}$. For dogs TiN PIRAC coated head against UHMWPE model was used while Wistar rats underwent THA on two legs using metalon-metal combination. Dogs were kept in open space four weeks after surgery.

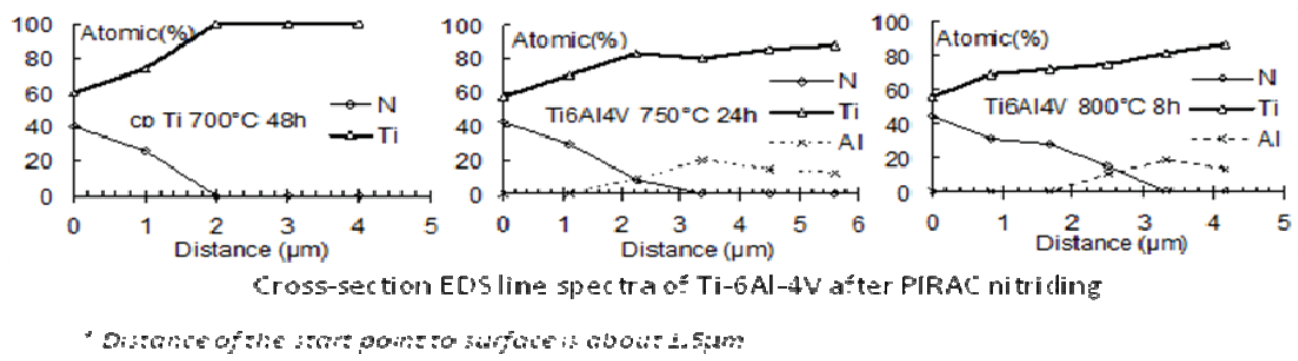

FIGURE 4. Composition as a function of distance from the surface obtained from EDS measurements for Ti6Al4V alloy PIRAC nitrided at $700^{\circ} \mathrm{C}, 750^{\circ} \mathrm{C}$ and $800^{\circ} \mathrm{C}$ 


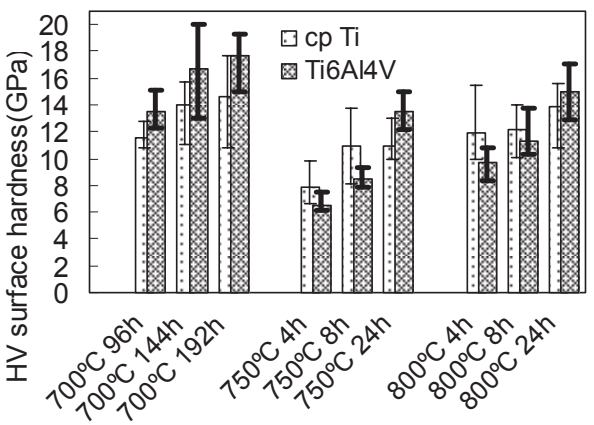

FIGURE 5. Vickers microhardness of cp-Ti and Ti6A14V PIRAC nitrided at various temperatures

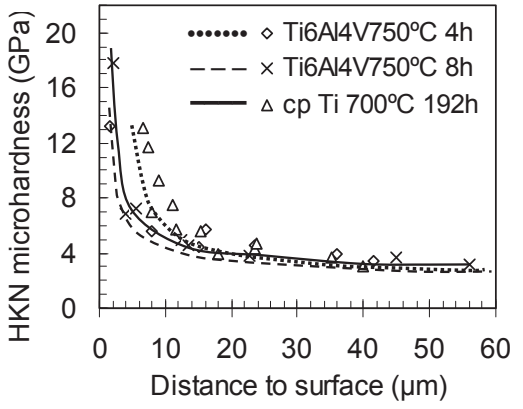

FIGURE 6. Knoop microhardness of PIRAC nitrided cp-Ti and Ti6Al4V as function of distance from the surface

In addition to normal walking and running rats were running for up to 14 weeks 2 hours per day on treadmill before sacrifice surgery. According to estimations till sacrifice implanted articulations made up to $8 \times 10^{6}$ cycles. Sacrifice surgery for dogs was performed 3.5 years after implantation. X-ray radiology was used during follow up. SEM/EDS analysis was performed of the surfaces of the extracted head, stem and cup. Histological analysis of the extracted femur was made. Osteolysis was estimated by hematoxylin and eosin staining. XRD analysis of the head surfaces was performed too. X-ray pictures after implantation surgery and optical photographs of total hip implants for dogs and Wistar rats are shown in Fig. 3.

Microstructure characterization of PIRAC-coated samples was performed using scanning electron microscopy SEM. and high resolution SEM-HRSEM. X-ray diffraction-XRD was employed for phase identification. Diffusion profiles of elements in the surface layers of the coated sample were measured by quantitative electron probe X-ray microanalysis EDS. Mechanical properties were studied employing "Instron" testing machine. The adhesion of PIRAC coatings to the substrates was estimated in a three point bending test. Microhardness (surface and of the cross section) of the coated samples was measured under a load of $25 \mathrm{gf}$ using a Knoop diamond indenter.

\section{RESULTS}

\section{TiN based coatings on Ti alloys at lower temperatures and 3 stage TiN PIRAC coating of Ti alloys}

To provide durable service to TiN PIRAC coated orthopaedic implants thick several micron coatings are needed. Since PIRAC is a reactive diffusion process, thickness of the coating at given temperature is proportional to square route of time. Longer exposures at temperatures above $850^{\circ} \mathrm{C}$ may result in coarsening of microstructure and lead to decrease of fatigue strength. To fabricate thicker coatings at lower temperatures long exposures are required.

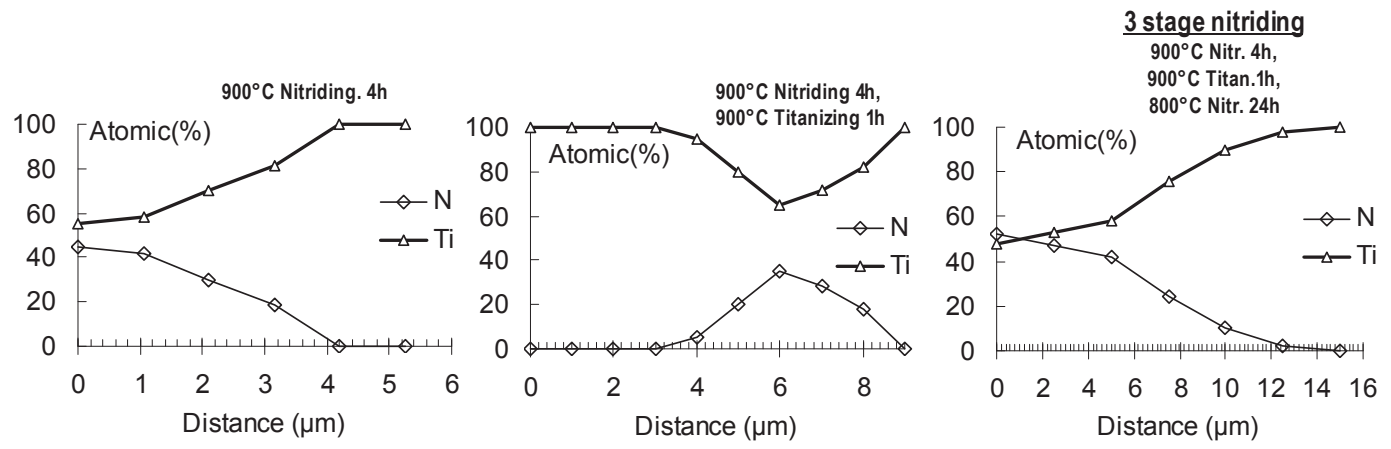

EDS line spectra of polished cross-section of cp Ti after different PIRAC treatment

FIGURE 7. Composition as a function of distance from the surface obtained from EDS measurements for Ti6A14V alloy PIRAC nitrided in 3 stages 


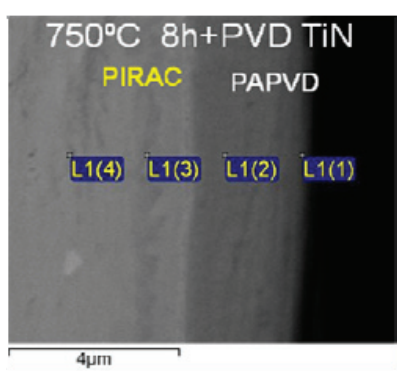

(a)

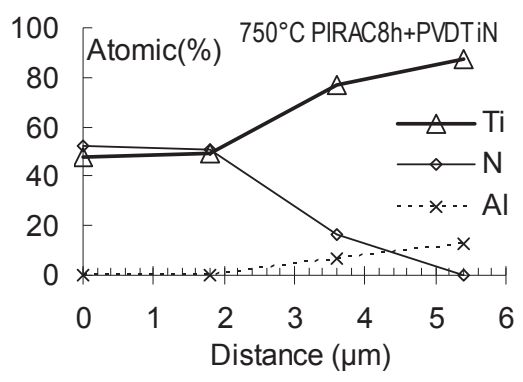

(b)

FIGURE 8. SEM micrograph of cross section (a) and composition a function of the distance from the surface are shown for the same specimen (b)

In Fig. 4 composition as a function of distance from the surface obtained from EDS measurements is shown for Ti6Al4V alloy PIRAC nitrided at $700^{\circ} \mathrm{C}, 750^{\circ} \mathrm{C}$ and $800^{\circ} \mathrm{C}$ for 48,24 and $8 \mathrm{~h}$ correspondingly. It can be seen that similar thickness of the coating is observed after treatment at $750^{\circ} \mathrm{C}$ and $800^{\circ} \mathrm{C}$. In Fig. 5 surface Vickers microhardness of cp-Ti and Ti6A14V PIRAC nitrided at various temperatures is presented. It can be seen that the highest microhardness is observed after long $192 \mathrm{~h}$ PIRAC nitriding at $700^{\circ} \mathrm{C}$. In Fig. 6 Knoop microhardness of PIRAC nitrided cp-Ti and Ti6Al4V as function of distance from the surface is shown. The highest hardness in deeper layer from the surface is observed for cp-Ti after $192 \mathrm{~h}$ PIRAC nitriding at $700^{\circ} \mathrm{C}$.

In Fig. 7 composition as a function of distance from the surface obtained from EDS measurements is shown for Ti6A14V alloy PIRAC nitrided in three stages: PIRAC nitriding at $900^{\circ} \mathrm{C}$ for $4 \mathrm{~h}$, followed by PIRAC titanization for $1 \mathrm{~h}$ at $900^{\circ} \mathrm{C}$ and followed by additional PIRAC nitriding at $800^{\circ} \mathrm{C}$ for $24 \mathrm{~h}$. The 2 nd stage - PIRAC titanizing for $1 \mathrm{~h}$ at $900^{\circ} \mathrm{C}$ results in $4 \mu \mathrm{m}$ Ti rich layer and 3rd stage-PIRAC nitriding results in nitrogen diffusion into the Ti rich layer, produced during 2nd stage from inside - the TiN layer formed during 1st stage and from outside monoatomic nitrogen. 3 stage PIRAC nitriding can be used for faster formation of thicker TiN based hard coatings

\section{Duplex TiN PIRAC-PVD coatings on Ti6Al4V alloy}

To obtain thick coatings in relatively short time duplex TiN coatings were fabricated on Ti6Al4V alloy: PIRAC nitriding was followed by $2 \mu \mathrm{m}$ PVD coating. In Fig. 8 SEM micrograph of cross section (a) and composition a function of the distance from the surface are shown for the same specimen (b). It was shown that no delamination takes place in 3 point bending test of duplex coatings while for TiN coatings processed via PVD the TiN coating delaminates in the same 3 point bending test (see Fig. 9), indicating good bonding integrity between TiN layer produced by PIRAC having excellent adhesion to Ti alloy substrates and TiN layer produced by PVD. CoCrMo alloy was PIRAC titanized at $900^{\circ} \mathrm{C}$ for 1 to $4 \mathrm{~h}$ (1st stage), followed by PIRAC nitriding at $900^{\circ} \mathrm{C}$ for $2 \mathrm{~h}$. The result shows that hard TiN based coatings can be produced via PIRAC on CoCrMo alloy implants.

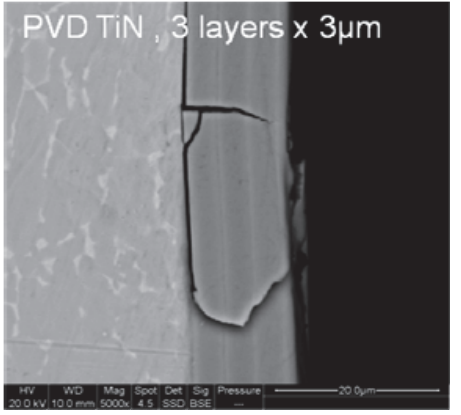

FIGURE 9. Delamination of PVD TiN coating from Ti6Al4V substrate in 3 point bending test

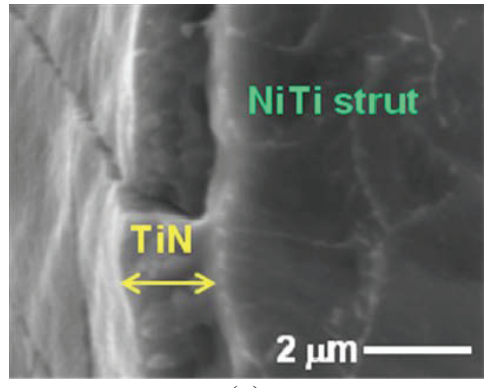

(a)

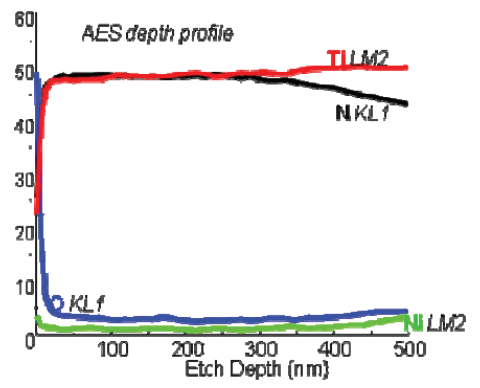

(b)

FIGURE 10. SEM micrograph of PIRAC TiN coated Nitinol (a) and Auger (AES) depth profile of coating (b) 


\section{Performance of THA implants in vivo-canine/dog and rat models}

It was shown that there is practically no visible or measurable wear of THA implants after more than $8 \times 10^{6}$ cycles for Wistar rats as well as after 3.5 years after surgery for dogs. Clinical and radiological follow up for dogs was uneventful and the dogs maintained normal gait pattern until sacrificed-3.5 years after surgery.

\section{Conversion of Ni foam into Nitinol foam followed by PIRAC nitriding}

Ni foam was converted to Nitinol foam by titanizing at temperatures $800^{\circ} \mathrm{C}-900^{\circ} \mathrm{C}$ according to the schematic in Fig. 2. This was followed by PIRAC nitriding resulting in formation of TiN coating on the surface, Ten fold decrease of toxic Ni ions release into physiological solution was observed [27, 28]. SEM micrograph of PIRAC TiN coated Nitinol is presented in Fig. 10(a) and Auger (AES) depth profile of such coating in Fig. 10(b).

PIRAC nitriding was successfully used also for nitriding of TiNb alloys, $\mathrm{Zr}$ and $\mathrm{Zr}-2.5 \mathrm{Nb}$ alloy. Two stage coating by wear resistant TiN based layer can be applied to steels, BCC metals such as Mo and W and Ni based superalloys.

\section{REFERENCES}

1. D. Dawson, S. Taheri, and N. C. Wallbridge, Wear 119, 277 (1987).

2. L. Que and L. D. Topoleski, Biomed. Mater. Res. 50, 322.

3. M. Levesque, B. J. Livingstone, W. M. Jones, and M. Spector, Trans. Orthop. Soc. 23, 247 (1998).

4. J. A. Davison, Clin. Orthop. 294, 361 (1993).

5. T. P. Schmalzried, D. L. Scott, C. A. Zahiri, et al., Trans. Orthop. Res. Soc. 23, 275 (1998).

6. B. S. Bal, J. Garino, M. Ries, and H. Oonishi, J. Knee Surg. 20(4), 261 (2007).

7. G. Willmann, Adv. Eng. Mater. 2(3), 114 (2000).

8. L. Savarino, M. Greco, E. Cenni, et al., J. Bone Joint Surg. Br. 88B, 472 (2006).

9. S. Greenwald and J. Garino, J. Bone Joint Surg. 83A(Suppl. 2, Part 2), 68 (2001).

10. P. A. Deamley, Proc. Inst. Mech. Eng. H 213, 107 (1999).

11. S. G. Psakhie, S. N. Meisner, A. I. Lotkov, L. L. Meisner, and A. V. Tverdokhlebova, ASM Int. J. Mat. Eng. Perform. (2014), DOI 10.1007/s11665-014-1112-7.

12. S. G. Psakhie, A. I. Lotkov, S. N. Meisner, L. L. Meisner, V. P. Sergeev, and A. R. Sungatulin, Inorg. Mater. 4(5), 457 (2013).

13. L. L. Meisner, A. I. Lotkov, V. A. Matveeva, L. V. Artemieva, S. N. Meisner, and A. L. Matveev, Adv. Mater. Sci. Eng. (2012), DOI 10.1155/2012/706094.

14. J. E. Mahan, Physical Vapor Deposition of Thin Films (Wiley, New York, 2000).

15. I. Brown, Ann. Rev. Mater. Sci. 28, 243 (1998).

16. K. S. Sree Harsha, Principles of Physical Vapor Deposition of Thin Films (Elsevier, Oxford, 2006).

17. P. J. Kelly and R. D. Amell, Vacuum, 56, 159 (2000).

18. G. Hunter, W.,M. Jones, and M. Spector, in Total Knee Arthroplasty, edited by J. Bellemans, M. D. Reis, J. Victor (Springer, Heidelberg, 2005), p. 370.

19. N. P. Sheth, P. Lementowski, G. Hunter, and J. P. Garino, J. Surg. Orthop. Adv. 17(1), 17 (2000).

20. S. P. Buyakova, D. S. Nikitin, V. A. Zhukov, V. V. Perkov, S. N. Kulkov, Inorg. Mater. 40(7), 760 (2004).

21. S. N. Kulkov, Nucl. Instrum. Meth. A 575(1-2), 109 (2007).

22. A. Shenhar, I. Gotman, E. Y. Gutmanas, and P. Ducheyne, Mater. Sci. Eng. A 268, 40 (1999).

23. D. Starosvetsky, I. Gotman, and A. Shenhar, J. Mater. Sci.: Mater. Med. 12, 145 (2001).

24. G. Sovak, A. Weiss, and I. Gotman, J. Bone Joint Surgery B 82, 290 (2000).

25. E. Y. Gutmanas and I. Gotman, J. Mater. Sci.: Mater. Med. 15, 327 (2004).

26. B. D. Goldman and E. Y. Gutmanas, Powder Met. Int. 13, 269 (1985).

27. I. Gotman, Adv. Biomater. B 12(7), 320 (2010).

28. I. Gotman, D. Ben-David, R. E. Unger, T. Bose, E. Y. Gutmanas, and C. J. Kirkpatrick, Acta Biomater. 9, 8440 (2013). 